\title{
Exosome mimetics: a novel class of drug delivery systems
}

\author{
This article was published in the following Dove Press journal: \\ International Journal of Nanomedicine \\ 15 March 2012 \\ Number of times this article has been viewed
}

\section{Sander AA Kooijmans \\ Pieter Vader \\ Susan $M$ van Dommelen \\ Wouter $W$ van Solinge \\ Raymond M Schiffelers}

Department of Clinical Chemistry and Haematology, University Medical Center Utrecht, Utrecht, The Netherlands
Correspondence: Raymond M Schiffelers Room G 03550, PO Box 85500, 3508

GA Utrecht, The Netherlands

$\mathrm{Tel}+3$ I 887556512

Fax +3I 887555418

Email r.schiffelers@umcutrecht.nl
Abstract: The identification of extracellular phospholipid vesicles as conveyors of cellular information has created excitement in the field of drug delivery. Biological therapeutics, including short interfering RNA and recombinant proteins, are prone to degradation, have limited ability to cross biological membranes, and may elicit immune responses. Therefore, delivery systems for such drugs are under intensive investigation. Exploiting extracellular vesicles as carriers for biological therapeutics is a promising strategy to overcome these issues and to achieve efficient delivery to the cytosol of target cells. Exosomes are a well studied class of extracellular vesicles known to carry proteins and nucleic acids, making them especially suitable for such strategies. However, the considerable complexity and the related high chance of off-target effects of these carriers are major barriers for translation to the clinic. Given that it is well possible that not all components of exosomes are required for their proper functioning, an alternative strategy would be to mimic these vesicles synthetically. By assembly of liposomes harboring only crucial components of natural exosomes, functional exosome mimetics may be created. The low complexity and use of well characterized components strongly increase the pharmaceutical acceptability of such systems. However, exosomal components that would be required for the assembly of functional exosome mimetics remain to be identified. This review provides insights into the composition and functional properties of exosomes, and focuses on components which could be used to enhance the drug delivery properties of exosome mimetics.

Keywords: exosomes, extracellular vesicles, liposomes, drug delivery systems

\section{Introduction}

Cells are well known to communicate via soluble mediators or cell-cell contact, but in recent decades, intercellular communication through extracellular vesicles has also increasingly gained attention. The first notion of such vesicles arose when Wolf described the formation of "platelet dust" upon storage of blood platelets. ${ }^{1}$ These phospholipid-rich particles were shown to exert coagulant activity and were later determined to be actively shed membrane-derived vesicles. ${ }^{2}$ Since then our knowledge about such vesicles has expanded dramatically, and vesicle secretion is now widely accepted to occur in most, if not all, cell types. Characterization studies identified three main populations of extracellular vesicles, which are commonly classified based on their intracellular origin. Cells that undergo apoptosis fractionate their cellular content into subcellular apoptotic bodies in order to prevent leakage of possibly toxic or immunogenic cellular contents into the extracellular matrix (Figure 1, left panel). ${ }^{3}$ Apoptotic bodies appear as a heterogeneous group of vesicles, with sizes ranging from $50 \mathrm{~nm}$ to $5 \mu \mathrm{m}$ and a buoyant density of $1.16-1.28 \mathrm{~g} / \mathrm{mL}^{4-7}$ They contain a variety 


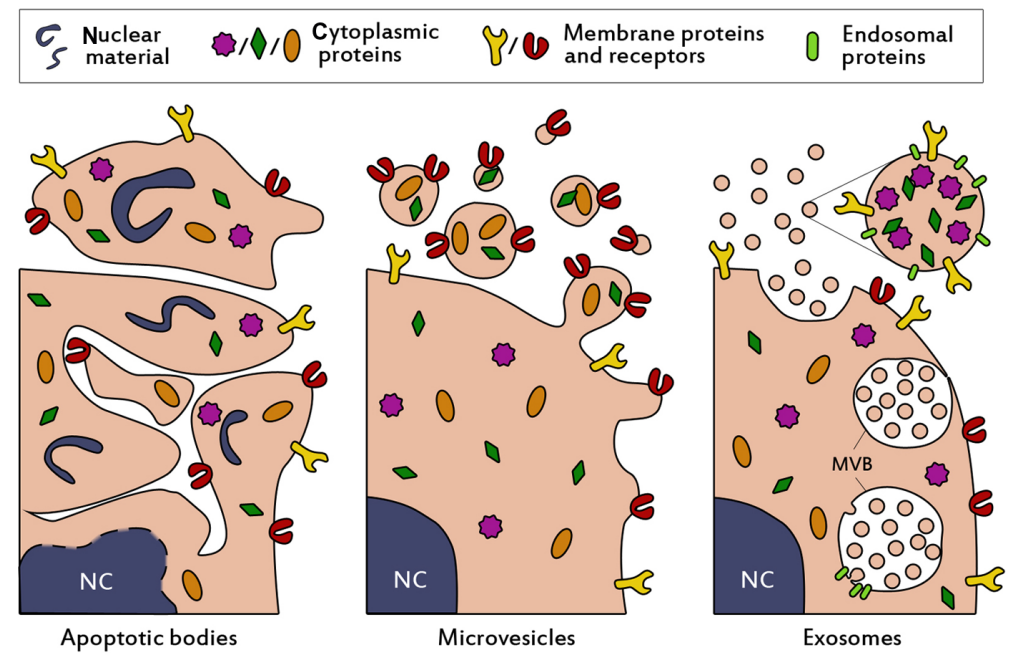

Figure I Schematic presentation of the biogenesis and composition of the three main classes of extracellular vesicles. Apoptotic bodies (left panel) are formed when cells enter apoptosis, and may contain nuclear material such as histones and DNA. They are heterogenous in size (50-5000 nm), irregularly shaped and harbor a variety of cellular proteins. Microvesicles (middle panel) are formed by budding and subsequent fission of the plasma membrane. Selective incorporation of membrane proteins and cytosolic proteins takes place during formation, resulting in vesicles which may be enriched in specific proteins and lipids compared to the parent cell. Microvesicles are thought to be smaller than apoptotic bodies $(50-1000 \mathrm{~nm}$ ) and more homogenously shaped. Selective enrichment of cellular content also occurs during the formation of exosomes (right panel), however exosomes originate from budding into the limiting membrane of large endosomal structures named multivesicular bodies (denoted with MVB). This process is facilitated by endosomal proteins. Subsequent fusion of MVBs with the plasma membrane results in release of the exosomes. Exosomes are small ( $<100$ nm), relatively homogenous in size, and may contain (endosomal) proteins involved in their assembly, such as CD9, Alix and TSGI0I.

Abbreviation: NC, nucleus.

of cellular contents, including DNA, RNA, and histones, and display "eat-me" signaling molecules, causing them to be rapidly cleared by macrophages. ${ }^{8,9}$ Due to their specific cellular content and high density, they may be distinguished from two other major vesicle populations, which show considerably more overlap.

One of these populations originates from budding and fission from the plasma membrane into the extracellular space (Figure 1, middle panel) and contains vesicles of about 50-1000 $\mathrm{nm}$ in size. Such vesicles are interchangeably referred to as microvesicles, ${ }^{10}$ ectosomes,${ }^{11}$ shedding vesicles, ${ }^{12}$ microparticles, ${ }^{13,14}$ plasma membrane-derived vesicles, ${ }^{15}$ or even exovesicles. ${ }^{16}$ In order to avoid confusion and promote standardization of nomenclature, the term "microvesicles" will be used in this review to denote this vesicle population. The buoyant density of microvesicles is still not well defined ${ }^{7}$ and also the intracellular mechanisms for vesicle release remain unclear. Microvesicle secretion may take place in resting cells, but the vesicle shedding rate increases dramatically upon stimulation. The stimuli and intensity of stimuli required for vesicle formation can vary among cell types. As a common principle, increasing intracellular levels of $\mathrm{Ca}^{2+}$ result in increased secretion of microvesicles. ${ }^{17,18}$ For example, erythrocytes can be stimulated with high levels of extracellular $\mathrm{Ca}^{2+}$ in combination with a suitable ionophore. ${ }^{19,20}$ In various human tumor cell lines, microvesicle production was increased at extracellular
$\mathrm{Ca}^{2+}$ concentrations up to $25 \mathrm{mM}$, but concentrations higher than $10 \mathrm{mM}$ also decreased cell viability. ${ }^{21}$ Other common stimulators for microvesicle release include lipopolysaccharide for monocytes, ${ }^{22}$ and activation of the $\mathrm{P} 2 \mathrm{X}_{7}$ receptor with ATP for macrophages and other myeloid cells..$^{23,24}$

The last population of secreted membrane vesicles comprises exosomes, which differ from microvesicles mainly in their intracellular origin. Whereas microvesicles are supposedly generated by budding from the plasma membrane, exosomes appear to be formed by tightly controlled inward budding into large multivesicular bodies in the cytosol. These multivesicular bodies are able to fuse with the plasma membrane, causing the release of exosomes into the extracellular space (Figure 1, right panel). ${ }^{25}$ In theory, exosomes and microvesicles are clearly distinguishable by their origin, but in practice such a distinction is seldom possible. Therefore, attempts are made to characterize and separate both populations based on phenotypical features, such as buoyant density, size, morphology, and protein and lipid composition. Exosomes typically share characteristics with the vesicles inside multivesicular bodies. They are commonly $40-100 \mathrm{~nm}$ in size, ${ }^{26}$ although somewhat larger diameters have been reported. ${ }^{27}$ When analyzed by electron microscopy, exosomes show a typical cupshaped morphology, ${ }^{28}$ but in biological fluids they are likely to exist as spherical structures. ${ }^{29}$ In addition to being more homogenous in size than microvesicles, they are thought to be more dense and float on a sucrose density gradient at heights 
of $1.13-1.19 \mathrm{~g} / \mathrm{mL} .{ }^{26}$ Furthermore, exosomes often contain specific proteins which are incorporated during the formation process in multivesicular bodies, such as Alix, TSG101, and tetraspanins (CD9, CD63), ${ }^{7,30}$ which are frequently used as markers for their identification.

Exosomes and microvesicles are involved in a large variety of body processes. They are concentrated carriers of genetic and proteomic information, and thus are believed to play important roles in intercellular communication. Secreted vesicles can transfer their messages in different ways. Firstly, they may activate target cells via ligands expressed on their surface. For example, it has been demonstrated that antigenpresenting exosomes derived from dendritic cells provoke $\mathrm{T}$ cell-mediated immune responses in vivo. ${ }^{31}$ In addition to eliciting immune responses, ligand-receptor signaling via exosomes can also play a role in other regulatory processes, such as angiogenesis, ${ }^{32}$ hemostasis, ${ }^{33}$ and cancer progression. ${ }^{34}$ Secondly, secreted vesicles may transfer surface receptors from one cell to another by budding and subsequent fusion with plasma membranes of target cells. ${ }^{35,36}$ This mechanism may be exploited by the human immunodeficiency virus, increasing susceptibility to infection by transferring CD4 receptors from infected cells to noninfected cells. ${ }^{37}$ Additionally, the shedding of microvesicles has been proposed to be a mechanism by which cells protect themselves from potentially harmful substances. ${ }^{12} \mathrm{~A}$ third mechanism of action is based on the horizontal transfer of proteins and genetic material, such as micro RNAs (miRNA), between cells. The cytosolic content of a donor cell can be transferred directly to the recipient cell following fusion or internalization of microvesicles and exosomes. ${ }^{38,39}$ This results in the release of cargo into the cytosol of the target cell and subsequent intracellular signaling. An example of protein transfer between cells has recently been presented by Sarkar et al, who elegantly demonstrated that the intracellular apoptotic protein caspase-1 was transferred between monocytes and vascular smooth muscle cells via microvesicles, inducing apoptosis in the latter. ${ }^{40}$ The encapsulation of caspase- 1 in microvesicles was shown to be necessary for the apoptotic effect of the enzyme.

First evidence of exosome-mediated transfer of mRNAs and miRNAs was recently presented by Valadi et al, who showed that exosomes from mouse mast cells contained substantial amounts of RNA. ${ }^{41}$ Many of the miRNAs were enriched compared with the parent cells, indicative of a selective incorporation process. Furthermore, mouse exosomes containing mRNA could be taken up by human mast cells, which resulted in the expression of mouse proteins in these cells. Additional evidence of functional miRNA transfer by exosomes was provided by Montecalvo et al, who showed that exosomes released from dendritic cells contained a variety of miRNAs. ${ }^{42}$ These exosomes were taken up by acceptor dendritic cells and effectively repressed target mRNA expression. Thus, while it has been suggested that only a minority of all circulating miRNA is confined within exosomes, ${ }^{43,44}$ exosomal miRNA may potently regulate gene expression in target cells in vivo. In addition to mRNA and miRNA, mitochondrial DNA (mtDNA) has been found in exosomes of astrocytes, myoblasts, and glioblastoma cells. ${ }^{45,46}$ Given that horizontal transfer of RNA by exosomes or microvesicles is important for cellular communication, vesicle-associated RNA may also serve as a diagnostic tool in disease. Disease states may cause specific miRNAs to be enriched in extracellular vesicles compared with healthy controls. For example, extracellular vesicles from patients with prostate cancer were selectively enriched in miR-141 compared with healthy controls, ${ }^{47}$ and EGFRvIII mRNA in circulating microvesicles was associated with clinically distinct subtypes of glioblastoma. ${ }^{48}$ Viral infections may also be detected by analysis of exosomal RNA content. ${ }^{49}$

Exosomes and microvesicles are naturally adapted for the transport and intracellular delivery of proteins and nucleic acids. This makes them particularly attractive for the delivery of pharmaceutical proteins and nucleic acids, such as short interfering RNA (siRNA). Intracellular delivery of siRNA is a challenging task, given that naked siRNAs are rapidly degraded in the circulation, their large size and negative charge limits membrane passage and cellular uptake, some siRNA sequence motifs may elicit undesired immune responses, and targeting to specific tissues and cells is required to reduce adverse effects caused by off-target silencing. ${ }^{50,51}$ Encapsulation of nucleic acid-based therapeutics in endogenous transporting vesicles is a promising novel strategy to overcome most of these delivery issues. Exosomes may be most suitable for such strategies, because they are small $(40-100 \mathrm{~nm})$, relatively homogenous in size, and well studied. Their size $<100 \mathrm{~nm}$ is advantageous for their use as drug delivery systems, because this allows them to evade rapid clearance by the mononuclear phagocyte system and enhances passage through fenestrations in the vessel wall, as might occur during inflammation. ${ }^{52}$

\section{Exosome-based drug delivery systems: biotechnological versus synthetic approaches}

The successful use of exosomes for the targeted delivery of siRNA has been recently demonstrated by 
Alvarez-Erviti et al. ${ }^{53}$ They harvested dendritic cells from mice and transfected them to express the neuronal targeting ligand, RVG, coupled to the exosomal membrane protein, Lamp2b. This protein was expressed by the cells and incorporated in secreted exosomes. The exosomes were harvested, purified, and loaded with siRNA against an important protein in Alzheimer pathogenesis (BACE1) by electroporation. When the modified exosomes were injected intravenously in wild-type mice, a $60 \%$ decrease of BACE1 mRNA in the brain cortex was observed after 3 days. This ultimately resulted in a decrease (55\%) of the harmful $\beta$-amyloid $1-42$ protein in the brain. Moreover, no increase in serum interleukin-6, interferon gamma-induced protein 10, tumor necrosis factor alpha and interferon alpha concentrations was observed after injection of the exosomes, suggesting that the modified exosomes were immunologically inert. However, immunological responses to repeated administration of exosomes were not evaluated, albeit repeated administration of exosomes loaded with siRNA against $G A P D H$ did not result in a loss of silencing efficiency.

The biotechnological approach to create exosome-based delivery systems used by Alvarez-Erviti et al was the first demonstration of an exosome-based drug delivery system which showed efficient in vivo delivery of siRNA..$^{53}$ Other strategies to exploit exosomes for therapeutic purposes have also been reported. In 2005, Delcayre et al described an "exosome display technology" in which various antigens were fused to the $\mathrm{C} 1 \mathrm{C} 2$ domain of lactadherin. ${ }^{54}$ This protein domain binds to the lipid phosphatidylserine exposed by exosomes, ${ }^{55}$ resulting in the presentation of the fused antigen to the immune system. When Chinese hamster ovary cells were transfected with fusion constructs of $\mathrm{C} 1 \mathrm{C} 2$ and interleukin-2 or granulocyte/monocyte colony-stimulating factor, the exosomes derived from these cells were significantly enriched with the recombinant cytokines compared with the parent cells. Moreover, the recombinant exosomes were able to induce proliferative responses in interleukin-2 and granulocyte/monocyte colony-stimulating factordependent cell lines, respectively. ${ }^{54}$ The therapeutic potential of 1 1C2-coupled antigen display by exosomes was further explored in subsequent studies. These showed that tumors secreting exosome-bound ovalbumin grew slower than tumors secreting soluble ovalbumin, due to an enhanced immune stimulatory effect of the former. ${ }^{56}$ Furthermore, the tumor-associated antigens, carcinoembryonic antigen and HER2, elicited potent antitumor immune responses when recombinantly coupled with exosomes. ${ }^{57}$ The antitumor potential of this approach was also demonstrated in two prostate cancer models, in which tumor growth was severely attenuated by vaccination with exosomes displaying the tumor antigens, prostate-specific antigen or prostatic acid phosphatase. ${ }^{58}$ The feasibility of antitumor therapy based on immunostimulatory exosomes was evaluated in two Phase I trials..$^{59,60}$ In these trials, dendritic cells of patients with stage III/IV melanoma were isolated and pulsed with MAGE3 tumor antigens. Exosomes presenting MAGE3 were isolated and readministered to melanoma patients. Therapy appeared to be well tolerated by all patients and induced the desired immune effects in some patients, showing clinical feasibility for exosome-based therapeutics.

In addition to $\mathrm{C} 1 \mathrm{C} 2$ coupling, therapeutics may also be nonspecifically bound to exosomes. This was recently demonstrated by Sun et al, who showed that mixing curcumin with exosomes enhanced its bioavailability, stability, and solubility, and improved its anti-inflammatory activity in an in vivo lipopolysaccharide-induced septic shock model compared with curcumin alone.$^{61}$ Furthermore, intranasally administered mouse lymphoma exosomes facilitated curcumin and stat 3 inhibitor delivery to brain microglia, inducing anti-inflammatory and antitumor effects, respectively. ${ }^{62}$

The examples mentioned above all use endogenous exosomes in their full complexity (or with only minimal modifications to their natural content) to deliver therapeutic cargo. This may offer a range of advantages over conventional drug delivery systems, such as viral or synthetic (nonviral) nanoparticles. Virus-based drug delivery systems have some of the advantages of natural viruses, including their excellent capacity to invade host cells and incorporate their viral load into the host genome. ${ }^{63}$ However, their potential for insertional mutagenesis or oncogenesis, high production costs, and risk of immunogenicity limit their clinical use. ${ }^{64}$ Nonviral drug delivery vehicles, such as cationic polyplexes and lipoplexes, are generally considered to be less immunogenic and mutagenic, but cytotoxicity and low transfection efficiencies in vivo are still major challenges to overcome..$^{64,65}$

Exosome-based drug delivery systems may provide unique advantages over other systems, including limited or no undesired immunogenicity when self-derived exosomes are used, greater stability in the blood due to evasion of complement and coagulation factors, ${ }^{66}$ efficient delivery of cargo into the cytosol of the target cell, and possibly fewer off-target effects due to the natural tendency of exosomes to act on specific target cells.

Despite these advantages, there are still some major obstacles and challenges to overcome before endogenous exosomes may be used in a clinical setting. Naturally derived 
exosomes are complex structures which are difficult to characterize pharmaceutically. In addition, they have complicated roles in health and disease, which are still poorly understood. ${ }^{27,67,68}$ Therefore, they may induce adverse effects when used in pharmaceutical preparations. Thorough characterization of exosome content and function is required to avoid such issues. Furthermore, biological fluids contain a mixture of extracellular vesicle populations from various cell types. The purification of single populations of cell-specific vesicles (eg, cancer cell-derived exosomes) still provides a barrier which hinders translation to the clinic. Highly purified populations of exosomes may be obtained from exosomesecreting cell lines, but such exosomes may lack "self" signals and elicit undesired immune responses. In addition, nanotechnological approaches for scalable production and efficient loading of exosomes are lacking, and remain an area of investigation. ${ }^{69}$

A viable alternative for biotechnologically tailored exosome-based drug delivery systems is synthetic exosome mimetics. It is well possible that not all components in natural exosomes are required for specific and efficient delivery of cargo to the target cell. By extensive characterization of the lipid, protein, and nucleic acid content of exosomes, only functional components could be used for selective incorporation in exosome mimetics. Given that natural exosomes exist as spherical lipid bilayer structures, liposomes would provide a logical basis for the generation of exosome mimetics. Similar to exosomes, liposomes are bilayered phospholipid structures with (adjustable) diameters around $100 \mathrm{~nm}$, which can be loaded with a variety of proteins, nucleic acids, or drug molecules. ${ }^{70,71}$ Liposomes have been shown to be valuable tools in drug delivery; several liposome-based drug delivery systems are currently in preclinical development and clinical trials, while others have been approved for clinical development. ${ }^{71}$ The tailoring of liposomes to mimic exosomes could therefore provide a springboard for a novel class of nonviral drug delivery systems. Such drug delivery systems would have the benefits of endogenous exosomes (eg, limited immunogenicity, efficient cargo delivery, enhanced stability in body fluids), but could limit some of the problems anticipated with biotechnologically engineered exosomes. Production of exosome mimetics is more easily scalable for use in preclinical or clinical settings. In addition, the assembly process of exosome mimetics is controllable and results in the formation of "clean", well characterized drug delivery systems with high pharmaceutical acceptability. Moreover, the use of exosome mimetics allows us to study the effect of each component separately. However, the components which are likely to be required for proper functioning of exosome mimetics as drug delivery systems are not yet well defined in the literature. Therefore, this review aims to describe potential candidate components for the assembly of functional exosome mimetics.

\section{Lipids}

In 2009, an initiative was undertaken by Mathivanan and Simpson to create an online database of all studies on exosomal protein and nucleic acid content, named ExoCarta. ${ }^{72}$ This allows scientists to catalogue exosome-specific proteomic and genomic data and makes them available to other scientists in the field. ExoCarta has grown steadily since its development, and now contains 134 studies covering data of 4049 proteins, 1639 mRNAs, and 764 miRNAs. Because it is increasingly understood that not only proteins and nucleic acids contribute to exosomal function, the feature to include data on exosomal lipids in the database has also recently been added..$^{73}$ At this moment, only a handful of lipids has been registered in ExoCarta, including four prostaglandins $\left(\mathrm{E}_{2}, \mathrm{~F}_{2}, \mathrm{~J}_{2}\right.$, and $\left.\mathrm{D}_{2}\right)$ and the conical lipid lysobisphosphatidic acid. Exosome-bound prostaglandins are involved in specific intracellular signaling pathways of the target cells $\mathrm{s}^{74}$ and thus do not appear to be essential for exosomal stability and delivery.

Likewise, it is unlikely that lysobisphosphatidic acid plays a functional role in circulating exosomes. Exosomes derived from rat mast cells, human dendritic cells, and B cells have been found to contain only minor amounts of this lipid compared with their parent cells. ${ }^{75,76}$ Rather, the lipid may be involved in exosome biogenesis at the multivesicular bodylimiting membrane, where its abundant presence has been shown. ${ }^{77,78}$ It has been postulated that lysobisphosphatidic acid could contribute to vesicle budding at this membrane, without being incorporated in the newly formed exosomes itself. ${ }^{79}$ In addition, the lipid may be involved in fusion of endocytosed vesicles with lysobisphosphatidic acid-containing endosomal membranes. It has been demonstrated that some infectious particles, including vesicular stomatitis and dengue viruses, fuse with late endosomes through interactions with lysobisphosphatidic acid, resulting in the release of their contents into the cytosol of the target cell. ${ }^{80-82}$ Thus, the activity of lysobisphosphatidic acid appears to be limited to intracellular fusion and budding processes.

The lipid bilayer of circulating exosomes appears to be mainly constituted of plasma membrane lipids, including sphingomyelin, phosphatidylcholine, phosphatidylethanolamine, phosphatidylserine, ganglioside GM3, and 
phosphatidylinositol. ${ }^{79}$ The ratios of these lipids vary among exosomes from different cell types. For instance, almost half of the lipids in exosomes derived from reticulocytes constitute phosphatidylcholine, ${ }^{83}$ whereas this lipid forms less than one third of total lipid content of mast cell-derived and dendritic cell-derived exosomes. ${ }^{75}$ In general, exosomes appear to be enriched in sphingomyelin, cholesterol, GM3, and phosphatidylserine compared with their parent cells. ${ }^{79}$ These lipids are not commonly used in liposomal drug delivery systems, but their incorporation can be advantageous. Sphingomyelin and cholesterol are thought to form hydrogen bonds, resulting in tight packing of sphingomyelin/cholesterol bilayers and low water permeability. ${ }^{84,85}$ In addition, they provide detergent resistance ${ }^{86}$ Therefore, incorporation of these lipids in exosome mimetics may increase their rigidity and stability. Indeed, liposomes containing sphingomyelin/cholesterol have longer circulation times and show decreased insertion of plasma proteins into their membrane. ${ }^{87}$ Liposomes containing sphingomyelin/cholesterol and loaded with vincristine have shown promising results in Phase II clinical trials, being tolerated at twice the dose of nonencapsulated vincristine in patients with aggressive non-Hodgkin lymphoma and showing a favorable side effect profile..$^{88,89}$

GM3 may act as a stabilizer of the exosomal wall and may shield the vesicle from interactions with blood components. Gangliosides, sphingomyelin, and cholesterol were demonstrated to act synergistically to decrease uptake of liposomes by the reticuloendothelial system both in vitro and in vivo. ${ }^{90,91}$ However, Yokoyama et al demonstrated with DPPG/GM3 liposomes that high molar concentrations $(>15 \mathrm{~mol} \%$ ) of GM3 may induce membrane segregation and leakage from vesicles. ${ }^{92}$ Therefore, GM3 may be beneficial in exosome mimetics when used in low concentrations only.

The structural function of phosphatidylserine in biological membranes is less well studied, but it is known to play a role as a signaling molecule in a large variety of biological processes. The biological role of phosphatidylserine may differ among vesicle populations and cellular sources. For instance, circulating erythrocytes gradually externalize phosphatidylserine during aging, providing an "eat-me" signal for the reticuloendothelial system. ${ }^{93}$ Allen et al showed that low concentrations of phosphatidylserine ( $>2 \mathrm{~mol} \%)$ in the membrane of erythrocyte-resembling liposomes were sufficient to induce clearance by this system dramatically, without affecting membrane lipid organization. ${ }^{94}$ The "eat-me" signaling function of phosphatidylserine is nature's way of clearing phosphatidylserine-exposing apoptotic cells by phagocytosis, reducing leakage of the cellular content to the extracellular matrix. ${ }^{95}$ The lipid may also serve as a docking station for factors of the coagulation cascade ${ }^{96}$ and has been suggested to play roles in other physiological processes, such as muscle formation and anti-inflammatory responses. ${ }^{97,98}$

Whilst these characteristics appear to be unfavorable for exosome mimetics, for which longer circulation times are often desired, incorporation of phosphatidylserine in exosome mimetics may be beneficial nonetheless. The natural conical shape of phosphatidylserine may aid in the assembly of the curved exosome mimetic membrane. ${ }^{99} \mathrm{In}$ addition, conically shaped lipids facilitate fusion and fission of biological membranes. ${ }^{100-102}$ Phosphatidylserine could thus enhance fusion of exosome mimetics with target cell membranes and promote intracellular release of cargo. Indeed, it has been shown in a number of studies that inhibition of phosphatidylserine on microvesicle membranes by Annexin-V or Diannexin reduced fusion of microvesicles with the plasma membranes of their target cells, ${ }^{36,38,103,104}$ indicating that phosphatidylserine is an important mediator of vesicle fusion. Moreover, it has been postulated that the negatively charged phosphatidylserine enhances the stability of cell membranes by electrostatic interactions with (cationic) skeletal proteins. ${ }^{105}$ This effect may be exploited in exosome mimetics loaded with cationic compounds, increasing the retention of encapsulated cargo. However, given that phosphatidylserine displayed on the outer layer of exosome mimetics may dramatically decrease their circulation time, incorporation of the lipid in exosome mimetics has to be carried out with caution.

Regardless of the exact lipid composition of extracellular vesicles, the lipid bilayer of exosomes appears to be adapted to their target environment. Extracellular pH may differ among target tissues, and rigidity of the vesicle needs to be maintained in these environments to assure optimal function. Parolini et al showed that exosomes released in an acidic microenvironment contained higher concentrations of sphingomyelin and GM3 compared with exosomes from the same cellular origin but released in a buffered environment. ${ }^{106}$ These lipids were suggested to increase exosomal rigidity upon interaction with cholesterol. ${ }^{107}$ Moreover, they demonstrated enhanced fusion of acidic exosomes with target cells compared with exosomes secreted in buffered conditions. Given that the target cells (metastatic melanoma) are surrounded by an acidic extracellular matrix under physiological conditions, ${ }^{106}$ this suggests that the lipid composition of exosomes may be tailored to their target microenvironment. The influence of extravesicular $\mathrm{pH}$ on exosome behavior was also demonstrated by Laulagnier et al, who showed that exosomal rigidity increased from 
$\mathrm{pH} 5$ to $\mathrm{pH} 7$, a common transition during release of exosomes from acidic multivesicular bodies. ${ }^{75}$ The rigid bilayer at physiological pH may enhance membrane fusion with target cells, but this was not investigated in this study.

\section{Proteins}

Although lipids are increasingly accepted to play important roles in exosomal function, exosome-associated proteins are indispensable. Such proteins can actively participate in regulatory processes and trigger cellular responses, but are also irrefutably involved in functional aspects of exosomes, such as assembly, (preventing) interaction with the extracellular matrix, and binding and fusion with target cells. For instance, it was demonstrated that cross-linking of proteins on exosomes by paraformaldehyde decreased exosomal fusion with parental cells by approximately $20 \% .{ }^{106}$ Furthermore, when these exosomes were solubilized with octylglucoside and reconstructed by dialysis (removing membrane proteins), they showed a dramatically reduced ability to fuse with target cells compared with untreated exosomes. The fusion efficiency of the proteindepleted exosomes was comparable with the fusion efficiency of large unilamellar vesicles with a lipid composition similar to that of the natural exosomes, confirming the importance of exosomal proteins in fusion events. ${ }^{106}$

According to a variety of proteomic studies (catalogued in ExoCarta), a number of proteins and protein families are abundantly detected in exosomes. ${ }^{30}$ Many of these, such as heat shock proteins, annexins, and proteins of the Rab family, are mainly involved in intracellular assembly and trafficking of exosomes and may not be required further after the vesicles are secreted. Thus, the inclusion of such proteins in exosome mimetics would probably not be beneficial for drug delivery purposes. However, several other exosomal proteins or protein families may be exploited to enhance the delivery properties of exosome mimetics. It should be noted that incorporation of proteins in exosome mimetics is still a challenging task, especially when simultaneous incorporation of multiple components is desired. However, work in this area is progressing and has yielded promising results. ${ }^{108-112}$ For instance, the functional reconstitution of a voltage-gated potassium channel and $\alpha_{\text {bII }} \beta_{3}$ integrin in giant unilamellar vesicles was recently described. ${ }^{108,110}$ The potential advantages of the incorporation of several exosomal proteins in exosome mimetics are discussed below.

\section{Tetraspanins}

Tetraspanins are a family of transmembrane proteins commonly detected in exosomes. Among them are CD9,
CD63, CD81, and CD82, which are often used as exosome markers. ${ }^{30,113}$ Some tetraspanins are selectively enriched in exosomes compared with their parent cells. An example is CD9, which was found to be more than 10-fold enriched in dendritic cell-derived exosomes. ${ }^{114}$ CD37, CD63, CD81, and CD82 were abundantly detected in exosomes derived from B lymphocytes. ${ }^{115}$ Atay et al demonstrated that CD81 was selectively enriched in exosomes from trophoblast cells, but could not detect CD63 (considered to be a canonical exosomal protein) in either parent cells or exosomes. ${ }^{116}$ Tetraspanin enrichment patterns in exosomes thus vary among parent cells.

Tetraspanins have been relatively understudied due to their limited ligand-receptor interaction and their small size, which in some cases may prevent biochemical or immunological detection. ${ }^{117}$ However, their functions as mediators of fusion, cell migration, cell-cell adhesion, and signaling events designate them as interesting targets in the field of drug discovery. ${ }^{118}$ Moreover, their functions in exosomes (albeit largely unknown) may be exploited to enhance the properties of exosome mimetics as drug delivery systems.

The tetraspanin, CD9, has been shown to mediate fusion processes in a variety of cell types. Miyado et al demonstrated that egg cells from CD9 knockout mice (CD9 ${ }^{-/}$) failed to fuse with sperm cells from wild-type males, although binding between the two cell types was unaltered. Normal fusion events were observed between sperm cells and $\mathrm{CD}^{+/+}$eggs, suggestive of an involvement of CD9 in the fusion process. Moreover, when CD9 on eggs was blocked with anti-CD9 antibodies, fusion was significantly inhibited. ${ }^{119}$ A role of CD9 in fusion processes was also evidenced by Tachibana and Hemler, who showed that blocking CD9 and CD81 on myoblast cells inhibited cell fusion to syncytia, and upregulation of the two tetraspanins resulted in enhanced cell fusion. ${ }^{120}$ It has been suggested that tetraspanin-mediated cell fusion is exploited by various viruses, allowing them to spread while avoiding exposure to the humoral immune system. ${ }^{121,122}$ However, the fusogenic properties of CD9 and CD81 were contradicted by studies of the fusion behavior of mononuclear phagocytes. Incubation of these cells with antibodies against CD9 and CD81 resulted in enhanced formation of multinucleated giant cells, and $\mathrm{CD}^{-/-}$and $\mathrm{CD} 81^{-/}$alveolar macrophages formed 3-4-fold more multinucleated giant cells than wild-type cells. ${ }^{123}$ These results were supported by Parthasarathy et al, who additionally showed that, in contrast with CD9 and CD81, CD63 in fact promoted monocyte fusion. ${ }^{124}$ Thus, the fusogenic properties of tetraspanins appear to be dependent on cell type. 
Interestingly, the tetraspanins which are often found to be enriched in exosomes (CD9, CD63, CD81, and CD82) $)^{30,113}$ have been shown to be involved in the migration of dendritic cells. In a chemotaxis assay, antibodies against the single tetraspanins increased migration of these cells by $50 \%-70 \%$, while $100 \%$ increased migration was observed when these antibodies were combined. ${ }^{125}$ The increase in migration was attributed to decreased binding of the cells to integrins expressed in the extracellular matrix. These results suggest that tetraspanins in exosomal membranes may facilitate their binding to target cells.

Although fusogenic and matrix-binding properties of tetraspanins in cell membranes have been described, not much is known about the functions of tetraspanins in exosomes. However, tetraspanins, Tspan8, CD49d, and CD106, appeared to be involved in binding and uptake of pancreatic adenocarcinoma-derived exosomes by fibroblasts and endothelial cells. ${ }^{126}$ It has also been suggested that CD9 is involved in fusion of exosomes with their target cells, ${ }^{52}$ indicating that tetraspanins may have similar functions in exosomes and cell membranes.

It is important to consider that tetraspanins probably exert most of their functions in unison with other membrane proteins. In cell membranes, tetraspanins are laterally organized in tetraspanin-enriched microdomains, which are resistant to mild detergent conditions. Tetraspanin-enriched microdomains generally contain integrins, signaling molecules, and other tetraspanins, and are involved in a variety of cell fusion, cell adhesion strengthening, and signaling events, as excellently reviewed previously. ${ }^{117,118,127,128}$ The effects of single tetraspanins, particularly in extracellular vesicles, are still poorly understood. Incorporation of tetraspanins in exosome mimetics may therefore not only enhance exosome mimetic functioning (ie, binding and uptake in target cells), but may also provide important clues on tetraspanin functioning in exosomes.

\section{Adhesion molecules}

According to the ExoCarta database, integrins are among the most abundant proteins detected in exosomes derived from cancer and immune cells. ${ }^{129}$ Integrins are membrane-spanning proteins which exist as heterodimers of $\alpha$ and $\beta$ subunits. A total of 24 different heterodimers have been identified in vertebrates, of which $\beta_{1}, \beta_{2}$, and $\alpha_{v}$ integrins comprise the largest group. They function primarily as adhesion molecules and establish cell binding to the extracellular matrix, although other functions have been described. ${ }^{130,131}$ In exosomes, integrins are most likely involved in addressing the vesicles to their target cells. ${ }^{31}$ Therefore, incorporation of integrins in exosome mimetics may potentiate their interactions with the extracellular matrix, increasing their delivery potential.

Given that integrins are abundantly detected in a range of exosomal preparations (especially those derived from cancer cells), ${ }^{132,133}$ it is surprising that only a limited number of studies have addressed the functional role of these adhesion molecules in exosomes. In seminal work by Rieu et al, it was shown that integrin $\alpha_{4} \beta_{1}$ is present on the surface of young reticulocytes and its surface levels decrease during maturation. ${ }^{134}$ The adhesion molecules of mature reticulocytes were detected in the exosomal fraction, suggesting that the cells use exosomes to dispose of integrins. Functional examination of the exosomes showed that $\alpha_{4} \beta_{1}$ integrin mediated binding of the exosomes to fibronectin. This binding was dependent on divalent cations $\left(\mathrm{Mg}^{2+}, \mathrm{Mn}^{2+}\right)$ and was significantly inhibited by the $\alpha_{4} \beta_{1}$-binding domain of fibronectin and anti- $\alpha_{4}$ antibodies. In similar work, it was found that exosomes from fibroblasts and epithelial cells contained $\beta_{1}$ integrins and that exosomes from human $\mathrm{B}$ cells expressed both $\beta_{1}$ and $\beta_{2}$ integrins. ${ }^{135} \mathrm{~B}$ cell-derived exosomes bound collagen I and fibronectin in a cationdependent manner, and binding was inhibited by antibodies against $\alpha_{4}$ and $\beta_{1}$ integrins. Moreover, it was shown that these exosomes strongly adhered to tumor necrosis factor alpha-stimulated fibroblasts through an integrin-intercellular adhesion molecule (ICAM-1) interaction. Integrin $\beta_{1}$ and CD9 were also detected on the surface of retroviral particles, and it was suggested that these contribute to adhesion of viruses to host cells. ${ }^{136}$ Taken together, these results suggest that exosomal integrins play a crucial role in establishing exosomal adhesion to the extracellular matrix. Given that binding to target cells is the first step in intracellular drug delivery, incorporation of integrins into exosome mimetics may thus greatly enhance their drug delivery potential. This strategy has not been implemented in drug delivery systems yet, but integrin-ligand interactions have been successfully exploited. For instance, the fibronectin-derived RGD peptide is commonly used to target drug delivery systems to $\alpha_{v} \beta_{3}$ integrin, which is overexpressed in tumor vasculature. ${ }^{137}$ Integrin incorporation in exosome mimetics may work in a similar fashion to deliver therapeutics to specific tissues. It has been shown that integrin $\alpha_{\mathrm{II}} \beta_{3}$ can be incorporated into liposomal membranes without losing its ability to bind to its ligands. ${ }^{109,138}$ However, the affinity of this integrin for its ligand, cyclo(RGDfV), was higher in cell membranes than in liposomes, ${ }^{139}$ suggesting that other endogenous membrane molecules (eg, tetraspanins, lipids) contribute 
to integrin-mediated adhesion. Indeed, such a synergistic effect was demonstrated in a study by Zheng et al, ${ }^{111}$ who incorporated integrin $\alpha_{5} \beta_{1}$ into phosphatidylcholine/cholesterol liposomes containing increasing concentrations of ganglioside GM3 (0-10 nmol/55 $\mu \mathrm{g}$ phosphatidylcholine). The binding of the liposomes to fibronectin-coated plates differed significantly among varying concentrations of GM3, and was optimal at GM3 concentrations of $0.2-0.4 \mathrm{nmol}$ $(0.22-0.44 \mu \mathrm{g}) / 55 \mu \mathrm{g}$ phosphatidylcholine. In addition, mammary carcinoma cells mutated to contain high concentrations of GM3 bound better to these plates than their parent cells, further evidencing the synergistic effect of other membrane components to integrin function. ${ }^{111}$ Given that the membranes of exosome mimetics resemble those of endogenous exosomes, integrin incorporation may be a powerful strategy to enhance the adhesive properties of exosome mimetics.

In addition to integrins, other adhesion molecules which may be potentially exploited in exosome mimetics have been identified in exosomes. Comprehensive proteomic studies have identified thrombospondin 1 in exosomes in the urine, plasma, and saliva of healthy volunteers. ${ }^{140-143}$ In addition, thrombospondin 1 and thrombospondin 2 were detected in exosomes from patients diagnosed with various types of cancer, and in exosomes derived from a colon cancer cell line. ${ }^{144,145}$ Thrombospondin 1 contains a variety of adhesive domains, including an RGD sequence that binds $\alpha_{\mathrm{v}} \beta_{3}$ integrins. ${ }^{146}$ Nucera et al demonstrated that the protein plays an important role in cancer metastasis. ${ }^{147}$ They showed that knockdown of the thrombospondin 1 gene in papillary thyroid carcinoma cells decreased their adhesion and migration in vitro and in vivo, and that treatment with a thrombospondin 1 inhibitor decreased metastasis and tumor growth in an orthotopic mouse model. In an attempt to use the adhesive properties of thrombospondins for targeted drug delivery, Rivera-Fillat et al developed aspartimide analogs of thrombospondin 1 and 2 and conjugated them to liposomes loaded with doxorubicin. ${ }^{148}$ Both peptides adhered to endothelial cells and colon carcinoma cells in vitro. In addition, it was demonstrated that the thrombospondin 1 analog enhanced the antitumor effect of doxorubicin-loaded liposomes in mice bearing a human colon carcinoma; tumor growth was inhibited and mouse survival was prolonged compared with the nontargeted doxorubicin liposomes. This effect was most likely due to enhanced delivery of doxorubicin to target cells, given that targeted liposomes without doxorubicin did not exert antitumoral activity. In addition to conferring adhesion properties, thrombospondins also serve as signaling molecules with antiangiogenic and antitumoral effects.
Therefore, they may have therapeutic potential on their own, and have been reviewed elsewhere. ${ }^{149,150}$ Thrombospondins may thus be valuable tools in tumor-targeted exosome mimetics; they may promote adhesion to target cells and induce antiangiogenic signaling pathways.

A third interesting class of adhesion molecules found associated with exosomes is the family of ICAMs. ICAM-1 and ICAM-3 have been detected in immune cell-derived exosomes ${ }^{41,115,151-153}$ and may function as important mediators in immune responses. ICAM-1 is a ligand for integrin $\alpha_{L} \beta_{2}$ (LFA-1) and Mac-1, and promotes leukocyte adhesion, ${ }^{154}$ while ICAM-3 binds DC-SIGN on dendritic cells. ${ }^{155}$ Their functions in exosomes are still under investigation, although some interesting results have been published. Segura et al showed that exosomes from mature dendritic cells contained markedly more ICAM-1 compared with those from immature dendritic cells. ${ }^{156}$ Mature exosomes induced T cell activation and proliferation in vitro, and enhanced $\mathrm{T}$ cell activation and skin graft rejection in vivo compared with immature exosomes. The authors showed that ICAM-1 expression was an important contributor to this process, and suggested that ICAM-1 mediates exosome adhesion to target antigen-presenting cells, thereby inducing the immune response. ${ }^{156}$ In a follow-up study, the group showed that ICAM-1-exposing exosomes induced significantly stronger $\mathrm{T}$ cell responses than ICAM-1 ${ }^{-/}$exosomes in vitro and in vivo, and that this effect was due to loss of exosome-cell adhesion mediated by ICAM-1 and LFA-1. ${ }^{157}$ These results demonstrate the importance of ICAM-1 in the adhesion of exosomes to LFA1-expressing immune cells. When targeting the immune system (eg, in vaccine preparations), the incorporation of ICAM-1 into exosome mimetics may be considered.

\section{Other membrane proteins}

Apart from tetraspanins and adhesion molecules, other proteins which also have the potential to enhance the drug delivery properties of exosome mimetics have been identified in exosomes. Two of these, CD55 and CD59, have been found in exosomes derived from various sources, including B cells, dendritic cells, colorectal cancer cells, saliva, and bronchial epithelial cells. ${ }^{66,141,145,153,158,159}$ Both factors protect cells from complement-mediated lysis; CD55 accelerates the decay of autologous complement factors, ${ }^{160}$ whereas CD59 prevents activation of the membrane attack complex by inhibition of C9 incorporation in C5b-9. ${ }^{161}$ In an interesting study by Clayton et al, it was demonstrated that inhibition of exosomal CD55 resulted in increased membrane disposition of $\mathrm{C} 3 \mathrm{~b}$ and exosome lysis. ${ }^{66}$ Blockade of CD59 also enhanced 
complement-mediated exosome lysis, and inhibition of both CD55 and CD59 increased lysis even further. These proteins thus appear to protect exosomes from complement-mediated lysis. Given that liposomes are prone to lysis mediated by complement factors, ${ }^{162,163}$ CD55 and CD59 may be used to improve the stability and circulation time of exosome mimetics.

Another exosomal protein with possible therapeutic applications is lactadherin (also known as EGF-factor VIII or MFG-E8). ${ }^{114}$ This protein is commonly found in exosomes derived from immune cells ${ }^{114,164,165}$ and fibroblasts. ${ }^{166}$ Lactadherin consists of two EGF-like domains and two lectin type $\mathrm{C}$ domains ( $\mathrm{C} 1$ and $\mathrm{C} 2)$ with high homology to coagulation factors $\mathrm{V}$ and VIII. ${ }^{167}$ The EGF-like domains mediate binding to integrins $\alpha_{\mathrm{v}} \beta_{3}$ and $\alpha_{\mathrm{v}} \beta_{5}$ via an RGD motif, while the $\mathrm{C} 2$ domain promotes binding to phosphatidylserine in biological membranes. ${ }^{168}$ Thus, it acts as a scaffold protein between the surface of phosphatidylserine-exposing apoptotic cells or exosomes and target cells. It has been reported that lactadherin promotes adhesion and uptake of exosomes by dendritic cells, ${ }^{169}$ but also interactions with other phagocytotic cells expressing integrins $\alpha_{\mathrm{v}} \beta_{3 / 5}$, such as macrophages and endothelial cells, are likely. ${ }^{114}$ To demonstrate that angiogenic endothelial cells are capable of phagocytosis, Fens et al prepared phosphatidylserine-exposing liposomes and opsonized them with lactadherin. ${ }^{170}$ Marked uptake of the opsonized liposomes in human umbilical vein endothelial cells was observed, whereas uptake was several-fold lower in the absence of lactadherin. Moreover, membrane vesicles containing egg phosphatidyl glycerol, which is a negatively charged phospholipid that lacks a lactadherin binding site, were barely taken up by human umbilical vein endothelial cells in the presence of the opsonin. These results show that lactadherin may be used to target exosome mimetics to specific integrin-expressing cells, such as angiogenic endothelial cells and dendritic cells.

Furthermore, it has been shown that fusion proteins containing the lactadherin $\mathrm{C} 1 \mathrm{C} 2$ domain can be exploited to induce immune responses to tumor antigens. ${ }^{56-58}$ In such strategies, the phosphatidylserine-binding domain of the opsonin is used to coat exosomes and exploit the excellent delivery potential of these vesicles to deliver the antigen to antigen-presenting cells, resulting in immune responses. These studies illustrate the versatility of the lactadherin protein and its application in exosome mimetic-mediated drug delivery. An advantage of lactadherin is that it does not need to be incorporated in the membrane of exosome mimetics. Rather, it is possible to produce the protein recombinantly ${ }^{171}$ and attach it to phosphatidylserine-exposing exosome mimetics after vesicle formation. Additionally, fusion proteins of lactadherin and functional domains of other proteins can be engineered, conferring unique properties to exosome mimetics coated with these constructs. For instance, by fusing the $\mathrm{C} 1 \mathrm{C} 2$ domain of lactadherin to targeting ligands, exosome mimetics may be targeted to specific organs and cell types. An additional advantage of lactadherin coating of phosphatidylserine-exposing exosome mimetics is that recognition of the lipid by phosphatidylserine receptors may be blocked. This way, the "eat-me" signaling function of phosphatidylserine would be inhibited, resulting in prolonged circulation time of the vesicles.

Decoration of exosome mimetics with specific proteins may also be achieved by the use of exosomal membrane anchors. In contrast with lactadherin, which is coated on the surface of exosome mimetics, such anchors may be plugged into the exosome mimetic membrane during exosome mimetic assembly and provide a stable scaffold for fused proteins. An example is Lamp2b, which was used by Alvarez-Erviti et al to anchor the neuron-specific RVG peptide to the exosomal membrane. ${ }^{53}$ Although this study exploited the endogenous exosomal pathway to incorporate the anchor into exosomes, it may be possible to reconstitute the protein into an artificial membrane (ie, exosome mimetic membrane). Thus, linkage of exosome mimetics to proteins which are not naturally expressed in exosomes may be achieved, circumventing possible expression issues in biotechnologically engineered exosomes. Such issues were clearly demonstrated by Shen et al, who attempted to target a highly oligomeric cytoplasmic protein (TyA-GFP) to secreted vesicles by fusing the protein to a variety of exosomal membrane proteins, including CD4, CD38, CD43, CD69, and CD83. ${ }^{172}$ After transfection of Jurkat $\mathrm{T}$ cells with expression vectors encoding the fusion proteins, only CD43-TyA-GFP could be weakly detected in the secreted vesicles. The authors suggested that endoplasmic reticulum-associated degradation could be responsible for the undetectable exosomal expression of some of the other constructs. A small number of constructs was degraded nor secreted, but was found to be retained in the endoplasmic reticulum instead. In this regard, the synthetic construction of exosome mimetics can offer a solution. A promising novel technique to incorporate membrane proteins into liposomes is the cell-free expression of such proteins in the presence of liposomes. ${ }^{173-175}$ Using this technique, integral membrane proteins are inserted into the liposomal membrane during their expression, resulting in functional and stable protein incorporation. Successful cell-free expression in liposomes 
has been demonstrated for a number of membrane proteins, such as membrane channel proteins. ${ }^{175-177}$

\section{Therapeutic cargo}

Exosome mimetics provide an opportunity to deliver therapeutic cargo directly into the cytoplasm of target cells. It is possible to load exosome mimetics with synthetic drugs, as is commonly done in other liposomal formulations, ${ }^{178,179}$ but the unique exosome-resembling characteristics of exosome mimetics allow them to excel in the delivery of therapeutic proteins and nucleic acids. An interesting class of molecules which could benefit from exosome mimetic-mediated delivery are miRNAs. These short noncoding endogenous RNA molecules recruit cellular proteins and bind to target mRNA sequences via Watson-Crick base-pairing, resulting in cleavage or translation repression of the target strand (RNA interference). This way, they regulate protein expression and cellular functioning. ${ }^{180}$ Given the discovery that miRNAs are not only involved in the regulation of cellular processes in the miRNA-producing cell, but that they also regulate processes in other cells by exosomal transfer, ${ }^{41}$ the therapeutic applications of miRNAs have gained increasing attention.

Intracellular levels of miRNAs have been extensively mapped in a number of diseases. Among the most studied diseases in this regard is cancer, in which specific miRNAs are often overexpressed or underexpressed compared with healthy cells. ${ }^{181}$ Low levels of cancer-associated miRNAs can be compensated by miRNA-based therapeutics (so-called miRNA restoration or replacement), resulting in improvement of the disease outcomes. Successful restoration of miRNA to treat various types of cancer has been described in a number of recent studies and was reviewed recently by Henry et al. ${ }^{182}$ For instance, in 2009, Kota et al showed that the expression of the miRNA, miR-26a, in liver tumors was markedly decreased compared with healthy liver tissue. ${ }^{183}$ To test whether restoration of miR-26a could have antitumorigenic effects, an adeno-associated virus vector packed with miR-26a was intravenously administered to liver tumorbearing mice. Three weeks after treatment, disease progression was dramatically decreased, cancer cell proliferation was inhibited, and tumor cell-specific apoptosis was increased compared with mice treated with empty vectors. The therapeutic effect of miRNA restoration was also shown for miR-34a, which was found to be underexpressed in prostate cancer cells. ${ }^{184}$ Upon repetitive intravenous administration of miR-34a complexed with a lipid-based delivery agent to mice with prostate cancer xenografts, tumor growth and metastasis were inhibited and mouse survival was prolonged. These effects were likely due to miR-34a-mediated downregulation of the adhesion molecule CD44 in tumor cells. ${ }^{184}$

While some miRNAs appear to be downregulated in various disease states, other miRNAs have been shown to be overexpressed. This phenomenon has supported the emergence of anti-miRNA-based therapeutics. ${ }^{185}$ These are antisense oligonucleotides with sequences complementary to those of the targeted miRNA, which disrupt miRNA biogenesis and functioning at multiple fronts (eg, miRNA processing and interactions with the target mRNA). ${ }^{186}$ Several interesting studies have effectively employed anti-miRNA strategies to induce cancer cell death and inhibit disease progression. ${ }^{187-191}$

These exciting results illustrate the potential of miRNAs and anti-miRNAs as a novel class of endogenous therapeutics. However, the intracellular delivery of (anti-)miRNAs is generally poor, and multiple (intratumoral) injections are often required for an effect. ${ }^{192,193}$ Given that exosomes are natural carriers for miRNAs, exosome mimetics would be excellent delivery systems for such molecules. Because their membrane resembles that of natural exosomes, the stability of encapsulated miRNAs could be increased. Furthermore, exosome mimetics may allow for nontoxic and nonimmunogenic delivery of their cargo to target cells, strongly potentiating the effects of (anti-)miRNAs.

Although miRNAs are promising therapeutic targets, it is important to note that they do not require full (100\%) binding to their target mRNA sequences for inhibiting effects. ${ }^{194}$ This allows them to act synergistically on various targets within signaling pathways, but also increases their chance for offtarget effects. These can be minimized by extensive characterization of possible target sequences and optimization of the administered miRNA doses. Alternatively, siRNA, which is known for its excellent sequence specificity, ${ }^{195}$ may be used to silence the expression of specific target genes. Similar to miRNA, the properties of siRNA (eg, their anionic charge, size, and rapid clearance) call for packaging in adequate delivery systems. Given that biotechnologically engineered exosomes have previously been successfully applied for delivery of siRNA, ${ }^{53}$ exosome mimetics hold great potential for siRNA-delivery.

\section{Conclusion and perspectives}

The safe and effective delivery of drug molecules to their target site is a field which has increasingly gained attention in drug design and development. In recent decades, the focus has shifted from synthetic drug compounds to the delivery of biological drugs (ie, proteins and nucleic acids), which are 
very prone to immune effects and degradation. In this regard, exosome mimetics are promising candidate delivery vehicles, given that they mimic nature's delivery vehicles of biologicals, but are not as complex as their biological counterparts. These characteristics may allow them to deliver biologicals in an effective and safe manner, with high pharmaceutical acceptability due to their well characterized components. However, before the full potential of exosome mimetics can be exploited, a number of challenges still need to be overcome. The assembly of liposomes with varying sizes and lipid compositions is commonly performed and well understood, but the incorporation of functional proteins and nucleic acids with reasonable efficiency is a field on its own. Membrane proteins have been successfully incorporated in liposomes without losing their functionality, ${ }^{108-112}$ but the incorporation of multiple proteins is a time-consuming and complicated process. Their membrane localization may require a specific lipid composition and chaperone proteins. Moreover, the (recombinant) production of membrane proteins is a challenging task due to their high hydrophobicity and cytotoxicity, tendency to form aggregates, and low expression levels. The use of promising cell-free expression systems may aid to overcome these production issues. ${ }^{173-175}$

For assembly of functional exosome mimetics, it is also important to take into account the structural and biological functions of the lipids to be incorporated. Lipids come in various sizes and shapes, which influence the behavior of the liposome in biological environments (eg, fusion and stability). In this regard, it may be wise to borrow a leaf from nature's book and mimic the lipid composition of exosomes in the intended target environment for optimal functionality. Increasingly powerful analytical methods in the field of lipidomics may aid in elucidating both function and composition of lipids in natural exosomes. These may provide valuable clues for drug delivery with exosome mimetics.

An additional challenge governing the assembly of functional exosome mimetics is the loading of therapeutic cargo. Although work is progressing in this area, high-efficiency loading of siRNA (and likewise miRNA) in lipid vesicles is still rarely achieved. ${ }^{196,197}$ Given that exosomes are loaded with multiple components that probably contribute to the outstanding delivery capacities of these vesicles, efficient loading of a combination of nucleic acids and proteins in exosome mimetics merits investigation. Furthermore, it is important to note that crucial components of exosomes are still largely unknown, and probably differ among exosomes with varying functions and target cells. The rapidly expanding field of exosomics allows us to increase our understanding of the composition and function of these intriguing vesicles, but is still in its infancy. Extensive proteomic studies have identified more than 4000 proteins and more than 1500 miRNAs in exosomes from various sources, but integrative studies are required to elucidate the biological functions of these components. The answer to "What makes natural exosomes such effective delivery vehicles?", is the first step towards the design and assembly of functional exosome mimetics.

\section{Acknowledgments}

The work of SAAK, PV, SMvD, and RMS on cell-derived membrane vesicles is supported by a European Research Council starting grant (260627) "MINDS" in the FP7 ideas program of the European Union.

\section{Disclosure}

The authors report no conflicts of interest in this work.

\section{References}

1. Wolf $P$. The nature and significance of platelet products in human plasma. Br J Haematol. 1967;13(3):269-288.

2. Crawford N. The presence of contractile proteins in platelet microparticles isolated from human and animal platelet-free plasma. $\mathrm{Br} J$ Haematol. 1971;21(1):53-69.

3. Doonan F, Cotter TG. Morphological assessment of apoptosis. Methods. 2008;44(3):200-204.

4. Hristov M, Erl W, Linder S, Weber PC. Apoptotic bodies from endothelial cells enhance the number and initiate the differentiation of human endothelial progenitor cells in vitro. Blood. 2004;104(9): 2761-2766.

5. Xie Y, Bai O, Yuan J, et al. Tumor apoptotic bodies inhibit CTL responses and antitumor immunity via membrane-bound transforming growth factor-beta1 inducing CD8+ T-cell anergy and CD4+ Tr1 cell responses. Cancer Res. 2009;69(19):7756-7766.

6. Cline AM, Radic MZ. Apoptosis, subcellular particles, and autoimmunity. Clin Immunol. 2004;112(2):175-182.

7. Thery C, Ostrowski M, Segura E. Membrane vesicles as conveyors of immune responses. Nat Rev Immunol. 2009;9(8):581-593.

8. Schiller M, Bekeredjian-Ding I, Heyder P, Blank N, Ho AD, Lorenz HM. Autoantigens are translocated into small apoptotic bodies during early stages of apoptosis. Cell Death Differ. 2008;15(1):183-191.

9. Gregory CD, Pound JD. Microenvironmental influences of apoptosis in vivo and in vitro. Apoptosis. 2010;15(9):1029-1049.

10. Muralidharan-Chari V, Clancy JW, Sedgwick A, D'Souza-Schorey C. Microvesicles: mediators of extracellular communication during cancer progression. J Cell Sci. 2010;123(Pt 10):1603-1611.

11. Pilzer D, Gasser O, Moskovich O, Schifferli JA, Fishelson Z. Emission of membrane vesicles: roles in complement resistance, immunity and cancer. Springer Semin Immunopathol. 2005;27(3):375-387.

12. Shedden K, Xie XT, Chandaroy P, Chang YT, Rosania GR. Expulsion of small molecules in vesicles shed by cancer cells: association with gene expression and chemosensitivity profiles. Cancer Res. 2003;63(15): 4331-4337.

13. Sekula M, Janawa G, Stankiewicz E, Stepien E. Endothelial microparticle formation in moderate concentrations of homocysteine and methionine in vitro. Cell Mol Biol Lett. 2011;16(1):69-78.

14. Shantsila E, Kamphuisen PW, Lip GY. Circulating microparticles in cardiovascular disease: implications for atherogenesis and atherothrombosis. J Thromb Haemost. 2010;8(11):2358-2368. 
15. Antwi-Baffour S, Kholia S, Aryee YK, et al. Human plasma membranederived vesicles inhibit the phagocytosis of apoptotic cells - possible role in SLE. Biochem Biophys Res Commun. 2010;398(2):278-283.

16. Obregon C, Rothen-Rutishauser B, Gitahi SK, Gehr P, Nicod LP. Exovesicles from human activated dendritic cells fuse with resting dendritic cells, allowing them to present alloantigens. Am J Pathol. 2006;169(6):2127-2136

17. Hugel B, Martinez MC, Kunzelmann C, Freyssinet JM. Membrane microparticles: two sides of the coin. Physiology (Bethesda). 2005;20: 22-27.

18. Bucki R, Bachelot-Loza C, Zachowski A, Giraud F, Sulpice JC. Calcium induces phospholipid redistribution and microvesicle release in human erythrocyte membranes by independent pathways. Biochemistry. 1998;37(44):15383-15391.

19. Gonzalez LJ, Gibbons E, Bailey RW, et al. The influence of membrane physical properties on microvesicle release in human erythrocytes. PMC Biophys. 2009;2(1):7.

20. Salzer U, Hinterdorfer P, Hunger U, Borken C, Prohaska R. Ca(++)dependent vesicle release from erythrocytes involves stomatin-specific lipid rafts, synexin (annexin VII), and sorcin. Blood. 2002;99(7): 2569-2577.

21. Crawford S, Diamond D, Brustolon L, Penarreta R. Effect of increased extracellular ca on microvesicle production and tumor spheroid formation. Cancer Microenviron. 2010;4(1):93-103.

22. Aharon A, Tamari T, Brenner B. Monocyte-derived microparticles and exosomes induce procoagulant and apoptotic effects on endothelial cells. Thromb Haemost. 2008;100(5):878-885.

23. Thomas LM, Salter RD. Activation of macrophages by P2X7-induced microvesicles from myeloid cells is mediated by phospholipids and is partially dependent on TLR4. J Immunol. 2010;185(6):3740-3749.

24. Wiley JS, Sluyter R, Gu BJ, Stokes L, Fuller SJ. The human P2X7 receptor and its role in innate immunity. Tissue Antigens. 2011;78(5):321-332.

25. Record M, Subra C, Silvente-Poirot S, Poirot M. Exosomes as intercellular signalosomes and pharmacological effectors. Biochem Pharmacol. 2011;81(10):1171-1182.

26. Simons M, Raposo G. Exosomes - vesicular carriers for intercellular communication. Curr Opin Cell Biol. 2009;21(4):575-581.

27. Taylor DD, Gercel-Taylor C. Exosomes/microvesicles: mediators of cancer-associated immunosuppressive microenvironments. Semin Immunopathol. 2011;33(5):441-454.

28. Sahoo S, Klychko E, Thorne T, et al. Exosomes from human CD34(+) stem cells mediate their proangiogenic paracrine activity. Circ Res. 2011;109(7):724-728.

29. Sokolova V, Ludwig AK, Hornung S, et al. Characterisation of exosomes derived from human cells by nanoparticle tracking analysis and scanning electron microscopy. Colloids Surf B Biointerfaces. 2011;87(1):146-150.

30. Simpson RJ, Jensen SS, Lim JW. Proteomic profiling of exosomes: current perspectives. Proteomics. 2008;8(19):4083-4099.

31. Thery C, Duban L, Segura E, Veron P, Lantz O, Amigorena S. Indirect activation of naive CD4+ T cells by dendritic cell-derived exosomes. Nat Immunol. 2002;3(12):1156-1162.

32. Martinez MC, Andriantsitohaina R. Microparticles in angiogenesis: therapeutic potential. Circ Res. 2011;109(1):110-119.

33. Aharon A, Brenner B. Microparticles, thrombosis and cancer. Best Pract Res Clin Haematol. 2009;22(1):61-69.

34. Cho JA, Park H, Lim EH, et al. Exosomes from ovarian cancer cells induce adipose tissue-derived mesenchymal stem cells to acquire the physical and functional characteristics of tumor-supporting myofibroblasts. Gynecol Oncol. 2011;123(2):379-386.

35. Baj-Krzyworzeka M, Majka M, Pratico D, et al. Platelet-derived microparticles stimulate proliferation, survival, adhesion, and chemotaxis of hematopoietic cells. Exp Hematol. 2002;30(5):450-459.

36. Al-Nedawi K, Meehan B, Kerbel RS, Allison AC, Rak J. Endothelial expression of autocrine VEGF upon the uptake of tumor-derived microvesicles containing oncogenic EGFR. Proc Natl Acad Sci USA 2009;106(10):3794-3799.
37. Ratajczak J, Wysoczynski M, Hayek F, Janowska-Wieczorek A, Ratajczak MZ. Membrane-derived microvesicles: important and underappreciated mediators of cell-to-cell communication. Leukemia. 2006;20(9):1487-1495.

38. Del Conde I, Shrimpton CN, Thiagarajan P, Lopez JA. Tissue-factorbearing microvesicles arise from lipid rafts and fuse with activated platelets to initiate coagulation. Blood. 2005;106(5):1604-1611.

39. Tian T, Wang Y, Wang H, Zhu Z, Xiao Z. Visualizing of the cellular uptake and intracellular trafficking of exosomes by live-cell microscopy. J Cell Biochem. 2010;111(2):488-496.

40. Sarkar A, Mitra S, Mehta S, Raices R, Wewers MD. Monocyte derived microvesicles deliver a cell death message via encapsulated caspase-1. PLoS One. 2009;4(9):e7140.

41. Valadi H, Ekstrom K, Bossios A, Sjostrand M, Lee JJ, Lotvall JO. Exosome-mediated transfer of mRNAs and microRNAs is a novel mechanism of genetic exchange between cells. Nat Cell Biol. 2007;9(6): 654-659.

42. Montecalvo A, Larregina AT, Shufesky WJ, et al. Mechanism of transfer of functional microRNAs between mouse dendritic cells via exosomes. Blood. 2012;119(3):756-766.

43. Arroyo JD, Chevillet JR, Kroh EM, et al. Argonaute2 complexes carry a population of circulating microRNAs independent of vesicles in human plasma. Proc Natl Acad Sci U S A. 2011;108(12): 5003-5008.

44. Turchinovich A, Weiz L, Langheinz A, Burwinkel B. Characterization of extracellular circulating microRNA. Nucleic Acids Res. 2011;39(16): $7223-7233$.

45. Guescini M, Genedani S, Stocchi V, Agnati LF. Astrocytes and glioblastoma cells release exosomes carrying mtDNA. J Neural Transm. 2010;117(1):1-4.

46. Guescini M, Guidolin D, Vallorani L, et al. C2C12 myoblasts release micro-vesicles containing mtDNA and proteins involved in signal transduction. Exp Cell Res. 2010;316(12):1977-1984.

47. Mitchell PS, Parkin RK, Kroh EM, et al. Circulating microRNAs as stable blood-based markers for cancer detection. Proc Natl Acad Sci US A. 2008;105(30):10513-10518.

48. Skog J, Wurdinger T, van Rijn S, et al. Glioblastoma microvesicles transport RNA and proteins that promote tumour growth and provide diagnostic biomarkers. Nat Cell Biol. 2008;10(12):1470-1476.

49. Pegtel DM, Cosmopoulos K, Thorley-Lawson DA, et al. Functional delivery of viral miRNAs via exosomes. Proc Natl Acad Sci U S A. 2010;107(14):6328-6333.

50. Castanotto D, Rossi JJ. The promises and pitfalls of RNA-interferencebased therapeutics. Nature. 2009;457(7228):426-433.

51. Baigude H, Rana TM. Delivery of therapeutic RNAi by nanovehicles. Chembiochem. 2009;10(15):2449-2454.

52. van den Boorn JG, Schlee M, Coch C, Hartmann G. SiRNA delivery with exosome nanoparticles. Nat Biotechnol. 2011;29(4):325-326.

53. Alvarez-Erviti L, Seow Y, Yin H, Betts C, Lakhal S, Wood MJ. Delivery of siRNA to the mouse brain by systemic injection of targeted exosomes. Nat Biotechnol. 2011;29(4):341-345.

54. Delcayre A, Estelles A, Sperinde J, et al. Exosome display technology: applications to the development of new diagnostics and therapeutics. Blood Cells Mol Dis. 2005;35(2):158-168.

55. Otzen DE, Blans K, Wang H, Gilbert GE, Rasmussen JT. Lactadherin binds to phosphatidylserine-containing vesicles in a two-step mechanism sensitive to vesicle size and composition. Biochim Biophys Acta. 2012;1818(4):1019-1027.

56. Zeelenberg IS, Ostrowski M, Krumeich S, et al. Targeting tumor antigens to secreted membrane vesicles in vivo induces efficient antitumor immune responses. Cancer Res. 2008;68(4):1228-1235.

57. Hartman ZC, Wei J, Glass OK, et al. Increasing vaccine potency through exosome antigen targeting. Vaccine. 2011;29(50):9361-9367.

58. Rountree RB, Mandl SJ, Nachtwey JM, et al. Exosome targeting of tumor antigens expressed by cancer vaccines can improve antigen immunogenicity and therapeutic efficacy. Cancer Res. 2011;71(15): 5235-5244. 
59. Escudier B, Dorval T, Chaput N, et al. Vaccination of metastatic melanoma patients with autologous dendritic cell (DC) derivedexosomes: results of the first phase I clinical trial. J Transl Med. 2005; 3(1): 10 .

60. Morse MA, Garst J, Osada T, et al. A phase I study of dexosome immunotherapy in patients with advanced non-small cell lung cancer. J Transl Med. 2005;3(1):9.

61. Sun D, Zhuang X, Xiang X, et al. A novel nanoparticle drug delivery system: the anti-inflammatory activity of curcumin is enhanced when encapsulated in exosomes. Mol Ther. 2010;18(9):1606-1614.

62. Zhuang X, Xiang X, Grizzle W, et al. Treatment of brain inflammatory diseases by delivering exosome encapsulated anti-inflammatory drugs from the nasal region to the brain. Mol Ther. 2011;19(10): 1769-1779

63. Ogawara K, Rots MG, Kok RJ, et al. A novel strategy to modify adenovirus tropism and enhance transgene delivery to activated vascular endothelial cells in vitro and in vivo. Hum Gene Ther. 2004;15(5): 433-443.

64. Kim WJ, Kim SW. Efficient siRNA delivery with non-viral polymeric vehicles. Pharm Res. 2009;26(3):657-666.

65. Singha K, Namgung R, Kim WJ. Polymers in small-interfering RNA delivery. Nucleic Acid Ther. 2011;21(3):133-147.

66. Clayton A, Harris CL, Court J, Mason MD, Morgan BP. Antigen-presenting cell exosomes are protected from complement-mediated lysis by expression of CD55 and CD59. Eur J Immunol. 2003;33(2):522-531.

67. Meckes DG Jr, Raab-Traub N. Microvesicles and viral infection. JVirol. 2011;85(24):12844-12854.

68. Camussi G, Deregibus MC, Bruno S, Grange C, Fonsato V, Tetta C. Exosome/microvesicle-mediated epigenetic reprogramming of cells. Am J Cancer Res. 2011;1(1):98-110.

69. Chen TS, Arslan F, Yin Y, et al. Enabling a robust scalable manufacturing process for therapeutic exosomes through oncogenic immortalization of human ESC-derived MSCs. J Transl Med. 2011;9:47.

70. Puri A, Loomis K, Smith B, et al. Lipid-based nanoparticles as pharmaceutical drug carriers: from concepts to clinic. Crit Rev Ther Drug Carrier Syst. 2009;26(6):523-580.

71. Fenske DB, Cullis PR. Liposomal nanomedicines. Expert Opin Drug Deliv. 2008;5(1):25-44.

72. Mathivanan S, Simpson RJ. ExoCarta: a compendium of exosomal proteins and RNA. Proteomics. 2009;9(21):4997-5000.

73. Mathivanan S, Fahner CJ, Reid GE, Simpson RJ. ExoCarta 2012: database of exosomal proteins, RNA and lipids. Nucleic Acids Res. 2012;40(Database issue):D1241-1244.

74. Subra C, Grand D, Laulagnier K, et al. Exosomes account for vesiclemediated transcellular transport of activatable phospholipases and prostaglandins. J Lipid Res. 2010;51(8):2105-2120.

75. Laulagnier K, Motta C, Hamdi S, et al. Mast cell- and dendritic cellderived exosomes display a specific lipid composition and an unusual membrane organization. Biochem J. 2004;380(Pt 1):161-171.

76. Wubbolts R, Leckie RS, Veenhuizen PT, et al. Proteomic and biochemical analyses of human B cell-derived exosomes. Potential implications for their function and multivesicular body formation. $J$ Biol Chem. 2003;278(13):10963-10972.

77. Alonso R, Mazzeo C, Rodriguez MC, et al. Diacylglycerol kinase alpha regulates the formation and polarisation of mature multivesicular bodies involved in the secretion of Fas ligand-containing exosomes in $\mathrm{T}$ lymphocytes. Cell Death Differ. 2011;18(7):1161-1173.

78. White IJ, Bailey LM, Aghakhani MR, Moss SE, Futter CE. EGF stimulates annexin 1-dependent inward vesiculation in a multivesicular endosome subpopulation. EMBO J. 2006;25(1):1-12.

79. Subra C, Laulagnier K, Perret B, Record M. Exosome lipidomics unravels lipid sorting at the level of multivesicular bodies. Biochimie. 2007;89(2):205-212.

80. Roth SL, Whittaker GR. Promotion of vesicular stomatitis virus fusion by the endosome-specific phospholipid bis(monoacylglycero)phosphate (BMP). FEBS Lett. 2011;585(6):865-869.
81. Zaitseva E, Yang ST, Melikov K, Pourmal S, Chernomordik LV. Dengue virus ensures its fusion in late endosomes using compartment-specific lipids. PLoS Pathog. 2010;6(10):e1001131.

82. Le Blanc I, Luyet PP, Pons V, et al. Endosome-to-cytosol transport of viral nucleocapsids. Nat Cell Biol. 2005;7(7):653-664.

83. Vidal M, Sainte-Marie J, Philippot JR, Bienvenue A. Asymmetric distribution of phospholipids in the membrane of vesicles released during in vitro maturation of guinea pig reticulocytes: evidence precluding a role for "aminophospholipid translocase". J Cell Physiol. 1989;140(3):455-462.

84. Needham D, Nunn RS. Elastic deformation and failure of lipid bilayer membranes containing cholesterol. Biophys J. 1990;58(4): 997-1009.

85. Ramstedt B, Slotte JP. Membrane properties of sphingomyelins. FEBS Lett. 2002;531(1):33-37.

86. Abi-Rizk G, Besson F. Interactions of Triton X-100 with sphingomyelin and phosphatidylcholine monolayers: influence of the cholesterol content. Colloids Surf B Biointerfaces. 2008;66(2):163-167.

87. Drummond DC, Meyer O, Hong K, Kirpotin DB, Papahadjopoulos D. Optimizing liposomes for delivery of chemotherapeutic agents to solid tumors. Pharmacol Rev. 1999;51(4):691-743.

88. Rodriguez MA, Pytlik R, Kozak T, et al. Vincristine sulfate liposomes injection (Marqibo) in heavily pretreated patients with refractory aggressive non-Hodgkin lymphoma: report of the pivotal phase 2 study. Cancer. 2009;115(15):3475-3482.

89. Boehlke L, Winter JN. Sphingomyelin/cholesterol liposomal vincristine: a new formulation for an old drug. Expert Opin Biol Ther. 2006;6(4):409-415.

90. Allen TM, Austin GA, Chonn A, Lin L, Lee KC. Uptake of liposomes by cultured mouse bone marrow macrophages: influence of liposome composition and size. Biochim Biophys Acta. 1991;1061(1):56-64.

91. Allen TM, Chonn A. Large unilamellar liposomes with low uptake into the reticuloendothelial system. FEBS Lett. 1987;223(1):42-46.

92. Yokoyama S, Takeda T, Tsunoda T, Ohta Y, Imura T, Abe M. Membrane properties of mixed dipalmitoylphosphatidylglycerol/ ganglioside GM3 liposomes in the presence of bovine serum albumin. Colloids Surf B Biointerfaces. 2003;27(2-3):141-146.

93. Schutters K, Reutelingsperger C. Phosphatidylserine targeting for diagnosis and treatment of human diseases. Apoptosis. 2010;15(9): 1072-1082.

94. Allen TM, Williamson P, Schlegel RA. Phosphatidylserine as a determinant of reticuloendothelial recognition of liposome models of the erythrocyte surface. Proc Natl Acad Sci U S A. 1988;85(21):8067-8071.

95. Pittoni V, Valesini G. The clearance of apoptotic cells: implications for autoimmunity. Autoimmun Rev. 2002;1(3):154-161.

96. Morel O, Jesel L, Freyssinet JM, Toti F. Cellular mechanisms underlying the formation of circulating microparticles. Arterioscler Thromb Vasc Biol. 2011;31(1):15-26.

97. Jeong J, Conboy IM. Phosphatidylserine directly and positively regulates fusion of myoblasts into myotubes. Biochem Biophys Res Commun. 2011;414(1):9-13.

98. Wu Z, Nakanishi H. Phosphatidylserine-containing liposomes: potential pharmacological interventions against inflammatory and immune diseases through the production of prostaglandin E(2) after uptake by myeloid derived phagocytes. Arch Immunol Ther Exp (Warsz). 2011;59(3):195-201.

99. Maxfield FR, McGraw TE. Endocytic recycling. Nat Rev Mol Cell Biol. 2004;5(2):121-132.

100. Chernomordik LV, Kozlov MM. Protein-lipid interplay in fusion and fission of biological membranes. Annu Rev Biochem. 2003;72: 175-207.

101. Papahadjopoulos D, Nir S, Duzgunes N. Molecular mechanisms of calcium-induced membrane fusion. J Bioenerg Biomembr. 1990;22(2): 157-179.

102. Hafez IM, Cullis PR. Roles of lipid polymorphism in intracellular delivery. Adv Drug Deliv Rev. 2001;47(2-3):139-148. 
103. Al-Nedawi K, Meehan B, Micallef J, et al. Intercellular transfer of the oncogenic receptor EGFRvIII by microvesicles derived from tumour cells. Nat Cell Biol. 2008;10(5):619-624.

104. Meckes DG Jr, Shair KH, Marquitz AR, Kung CP, Edwards RH, Raab-Traub N. Human tumor virus utilizes exosomes for intercellular communication. Proc Natl Acad Sci U S A. 2010;107(47):20370-20375.

105. Manno S, Takakuwa Y, Mohandas N. Identification of a functional role for lipid asymmetry in biological membranes: Phosphatidylserineskeletal protein interactions modulate membrane stability. Proc Natl Acad Sci U S A. 2002;99(4):1943-1948.

106. Parolini I, Federici C, Raggi C, et al. Microenvironmental $\mathrm{pH}$ is a key factor for exosome traffic in tumor cells. J Biol Chem. 2009;284(49) 34211-34222.

107. Niemela PS, Ollila S, Hyvonen MT, Karttunen M, Vattulainen I. Assessing the nature of lipid raft membranes. PLoS Comput Biol. 2007;3(2): 34

108. Aimon S, Manzi J, Schmidt D, Poveda Larrosa JA, Bassereau P, Toombes GE. Functional reconstitution of a voltage-gated potassium channel in giant unilamellar vesicles. PLoS One. 2011;6(10) e25529.

109. Erb EM, Tangemann K, Bohrmann B, Muller B, Engel J. Integrin alphaIIb beta3 reconstituted into lipid bilayers is nonclustered in its activated state but clusters after fibrinogen binding. Biochemistry. 1997;36(24):7395-7402.

110. Streicher P, Nassoy P, Barmann M, et al. Integrin reconstituted in GUVs: a biomimetic system to study initial steps of cell spreading. Biochim Biophys Acta. 2009;1788(10):2291-2300.

111. Zheng M, Fang H, Tsuruoka T, Tsuji T, Sasaki T, Hakomori S. Regulatory role of GM3 ganglioside in alpha 5 beta 1 integrin receptor for fibronectin-mediated adhesion of FUA169 cells. J Biol Chem. 1993;268(3):2217-2222

112. Varnier A, Kermarrec F, Blesneac I, et al. A simple method for the reconstitution of membrane proteins into giant unilamellar vesicles. J Membr Biol. 2010;233(1-3):85-92.

113. Raimondo F, Morosi L, Chinello C, Magni F, Pitto M. Advances in membranous vesicle and exosome proteomics improving biological understanding and biomarker discovery. Proteomics. 2011;11(4): 709-720.

114. Thery C, Regnault A, Garin J, et al. Molecular characterization of dendritic cell-derived exosomes. Selective accumulation of the heat shock protein hsc73. J Cell Biol. 1999;147(3):599-610.

115. Escola JM, Kleijmeer MJ, Stoorvogel W, Griffith JM, Yoshie O, Geuze HJ. Selective enrichment of tetraspan proteins on the internal vesicles of multivesicular endosomes and on exosomes secreted by human B-lymphocytes. J Biol Chem. 1998;273(32):20121-20127.

116. Atay S, Gercel-Taylor C, Kesimer M, Taylor DD. Morphologic and proteomic characterization of exosomes released by cultured extravillous trophoblast cells. Exp Cell Res. 2011;317(8):1192-1202.

117. Hemler ME. Tetraspanin functions and associated microdomains. Nat Rev Mol Cell Biol. 2005;6(10):801-811.

118. Hemler ME. Targeting of tetraspanin proteins - potential benefits and strategies. Nat Rev Drug Discov. 2008;7(9):747-758.

119. Miyado K, Yamada G, Yamada S, et al. Requirement of CD9 on the egg plasma membrane for fertilization. Science. 2000;287(5451) 321-324.

120. Tachibana I, Hemler ME. Role of transmembrane 4 superfamily (TM4SF) proteins CD9 and CD81 in muscle cell fusion and myotube maintenance. J Cell Biol. 1999;146(4):893-904.

121. Martin F, Roth DM, Jans DA, et al. Tetraspanins in viral infections: a fundamental role in viral biology? J Virol. 2005;79(17):10839-10851.

122. Gordon-Alonso M, Yanez-Mo M, Barreiro O, et al. Tetraspanins CD9 and CD81 modulate HIV-1-induced membrane fusion. J Immunol. 2006;177(8):5129-5137.

123. Takeda Y, Tachibana I, Miyado K, et al. Tetraspanins CD9 and CD8 function to prevent the fusion of mononuclear phagocytes. J Cell Biol. 2003;161(5):945-956.
124. Parthasarathy V, Martin F, Higginbottom A, et al. Distinct roles for tetraspanins CD9, CD63 and CD81 in the formation of multinucleated giant cells. Immunology. 2009;127(2):237-248.

125. Mantegazza AR, Barrio MM, Moutel S, et al. CD63 tetraspanin slows down cell migration and translocates to the endosomal-lysosomalMIICs route after extracellular stimuli in human immature dendritic cells. Blood. 2004;104(4):1183-1190.

126. Nazarenko I, Rana S, Baumann A, et al. Cell surface tetraspanin Tspan8 contributes to molecular pathways of exosome-induced endothelial cell activation. Cancer Res. 2010;70(4):1668-1678.

127. Hemler ME. Tetraspanin proteins mediate cellular penetration, invasion, and fusion events and define a novel type of membrane microdomain. Annu Rev Cell Dev Biol. 2003;19:397-422.

128. Zoller M. Tetraspanins: push and pull in suppressing and promoting metastasis. Nat Rev Cancer. 2009;9(1):40-55.

129. van Dommelen SM, Vader P, Lakhal S, et al. Microvesicles and exosomes: opportunities for cell-derived membrane vesicles in drug delivery. J Control Release. November 25, 2011. [Epub ahead of print.]

130. Barczyk M, Carracedo S, Gullberg D. Integrins. Cell Tissue Res. 2010; 339(1):269-280.

131. Campbell ID, Humphries MJ. Integrin structure, activation, and interactions. Cold Spring Harb Perspect Biol. 2011;3(3):a004994.

132. Hakulinen J, Sankkila L, Sugiyama N, Lehti K, Keski-Oja J. Secretion of active membrane type 1 matrix metalloproteinase (MMP-14) into extracellular space in microvesicular exosomes. $J$ Cell Biochem. 2008;105(5):1211-1218

133. Welton JL, Khanna S, Giles PJ, et al. Proteomics analysis of bladder cancer exosomes. Mol Cell Proteomics. 2010;9(6):1324-1338.

134. Rieu S, Geminard C, Rabesandratana H, Sainte-Marie J, Vidal M. Exosomes released during reticulocyte maturation bind to fibronectin via integrin alpha4beta1. Eur J Biochem. 2000;267(2):583-590.

135. Clayton A, Turkes A, Dewitt S, Steadman R, Mason MD, Hallett MB. Adhesion and signaling by B cell-derived exosomes: the role of integrins. FASEB J. 2004;18(9):977-979.

136. Segura MM, Garnier A, Di Falco MR, et al. Identification of host proteins associated with retroviral vector particles by proteomic analysis of highly purified vector preparations. J Virol. 2008;82(3):1107-1117.

137. Temming K, Schiffelers RM, Molema G, Kok RJ. RGD-based strategies for selective delivery of therapeutics and imaging agents to the tumour vasculature. Drug Resist Updat. 2005;8(6):381-402.

138. Meinecke R, Meyer B. Determination of the binding specificity of an integral membrane protein by saturation transfer difference NMR: RGD peptide ligands binding to integrin alphaIIbbeta3. J Med Chem 2001;44(19):3059-3065.

139. Claasen B, Axmann M, Meinecke R, Meyer B. Direct observation of ligand binding to membrane proteins in living cells by a saturation transfer double difference (STDD) NMR spectroscopy method shows a significantly higher affinity of integrin alpha(IIb)beta3 in native platelets than in liposomes. J Am Chem Soc. 2005;127(3): 916-919.

140. Gonzales PA, Pisitkun T, Hoffert JD, et al. Large-scale proteomics and phosphoproteomics of urinary exosomes. J Am Soc Nephrol. 2009;20(2):363-379.

141. Gonzalez-Begne M, Lu B, Han X, et al. Proteomic analysis of human parotid gland exosomes by multidimensional protein identification technology (MudPIT). J Proteome Res. 2009;8(3):1304-1314.

142. Pisitkun T, Shen RF, Knepper MA. Identification and proteomic profiling of exosomes in human urine. Proc Natl Acad Sci U S A 2004;101(36):13368-13373.

143. Looze C, Yui D, Leung L, et al. Proteomic profiling of human plasma exosomes identifies PPARgamma as an exosome-associated protein. Biochem Biophys Res Commun. 2009;378(3):433-438.

144. Bard MP, Hegmans JP, Hemmes A, et al. Proteomic analysis of exosomes isolated from human malignant pleural effusions. Am J Respir Cell Mol Biol. 2004;31(1):114-121. 
145. Mathivanan S, Lim JW, Tauro BJ, Ji H, Moritz RL, Simpson RJ. Proteomics analysis of A33 immunoaffinity-purified exosomes released from the human colon tumor cell line LIM1215 reveals a tissue-specific protein signature. Mol Cell Proteomics. 2010;9(2):197-208.

146. John AS, Rothman VL, Tuszynski GP. Thrombospondin-1 (TSP-1) stimulates expression of integrin alpha6 in human breast carcinoma cells: a downstream modulator of TSP-1-induced cellular adhesion. J Oncol. 2010;2010:645376.

147. Nucera C, Porrello A, Antonello ZA, et al. B-Raf(V600E) and thrombospondin-1 promote thyroid cancer progression. Proc Natl Acad Sci US A. 2010;107(23):10649-10654.

148. Rivera-Fillat MP, Reig F, Martinez EM, Grau-Oliete MR. Improved therapeutic responses for liposomal doxorubicin targeted via thrombospondin peptidomimetics versus untargeted doxorubicin. J Pept Sci. 2010;16(7):315-321.

149. Kazerounian S, Yee KO, Lawler J. Thrombospondins in cancer. Cell Mol Life Sci. 2008;65(5):700-712.

150. Zhang X, Lawler J. Thrombospondin-based antiangiogenic therapy. Microvasc Res. 2007;74(2-3):90-99.

151. Skokos D, Le Panse S, Villa I, et al. Mast cell-dependent B and T lymphocyte activation is mediated by the secretion of immunologically active exosomes. J Immunol. 2001;166(2):868-876.

152. Skokos D, Le Panse S, Villa I, et al. Nonspecific B and T cellstimulatory activity mediated by mast cells is associated with exosomes. Int Arch Allergy Immunol. 2001;124(1-3):133-136.

153. Buschow SI, van Balkom BW, Aalberts M, Heck AJ, Wauben M, Stoorvogel W. MHC class II-associated proteins in B-cell exosomes and potential functional implications for exosome biogenesis. Immunol Cell Biol. 2010;88(8):851-856.

154. Long EO. ICAM-1: getting a grip on leukocyte adhesion. J Immunol. 2011;186(9):5021-5023.

155. Svajger U, Anderluh M, Jeras M, Obermajer N. C-type lectin DCSIGN: an adhesion, signalling and antigen-uptake molecule that guides dendritic cells in immunity. Cell Signal. 2010;22(10):1397-1405.

156. Segura E, Nicco C, Lombard B, et al. ICAM-1 on exosomes from mature dendritic cells is critical for efficient naive T-cell priming. Blood. 2005;106(1):216-223.

157. Segura E, Guerin C, Hogg N, Amigorena S, Thery C. CD8+ dendritic cells use LFA-1 to capture MHC-peptide complexes from exosomes in vivo. J Immunol. 2007;179(3):1489-1496.

158. Choi DS, Lee JM, Park GW, et al. Proteomic analysis of microvesicles derived from human colorectal cancer cells. J Proteome Res. 2007;6(12):4646-4655.

159. Kesimer M, Scull M, Brighton B, et al. Characterization of exosomelike vesicles released from human tracheobronchial ciliated epithelium: a possible role in innate defense. FASEB J. 2009;23(6):1858-1868.

160. Brodbeck WG, Mold C, Atkinson JP, Medof ME. Cooperation between decay-accelerating factor and membrane cofactor protein in protecting cells from autologous complement attack. J Immunol. 2000;165(7):3999-4006.

161. Rollins SA, Sims PJ. The complement-inhibitory activity of CD59 resides in its capacity to block incorporation of $\mathrm{C} 9$ into membrane C5b-9. J Immunol. 1990;144(9):3478-3483.

162. Liu S, Ishida T, Kiwada H. Characterization of bovine serum factor triggering the lysis of liposomes via complement activation. Biol Pharm Bull. 1998;21(4):390-397.

163. Bradley AJ, Devine DV, Ansell SM, Janzen J, Brooks DE. Inhibition of liposome-induced complement activation by incorporated poly(ethylene glycol)-lipids. Arch Biochem Biophys. 1998;357(2):185-194.

164. Fevrier B, Vilette D, Archer F, et al. Cells release prions in association with exosomes. Proc Natl Acad Sci U S A. 2004;101(26):9683-9688.

165. Potolicchio I, Carven GJ, Xu X, et al. Proteomic analysis of microgliaderived exosomes: metabolic role of the aminopeptidase CD13 in neuropeptide catabolism. J Immunol. 2005;175(4):2237-2243.

166. Ji H, Erfani N, Tauro BJ, et al. Difference gel electrophoresis analysis of Ras-transformed fibroblast cell-derived exosomes. Electrophoresis. 2008;29(12):2660-2671.
167. Andersen MH, Graversen H, Fedosov SN, Petersen TE, Rasmussen JT. Functional analyses of two cellular binding domains of bovine lactadherin. Biochemistry. 2000;39(20):6200-6206.

168. Lin L, Huai Q, Huang M, Furie B, Furie BC. Crystal structure of the bovine lactadherin $\mathrm{C} 2$ domain, a membrane binding motif, shows similarity to the $\mathrm{C} 2$ domains of factor $\mathrm{V}$ and factor VIII. J Mol Biol. 2007;371(3):717-724.

169. Morelli AE, Larregina AT, Shufesky WJ, et al. Endocytosis, intracellular sorting, and processing of exosomes by dendritic cells. Blood. 2004;104(10):3257-3266.

170. Fens MH, Mastrobattista E, de Graaff AM, et al. Angiogenic endothelium shows lactadherin-dependent phagocytosis of aged erythrocytes and apoptotic cells. Blood. 2008;111(9):4542-4550.

171. Qiang X, Li J, Wu R, et al. Expression and characterization of recombinant human milk fat globule-EGF factor VIII. Int J Mol Med. 2011;28(6):1071-1076.

172. Shen B, Wu N, Yang JM, Gould SJ. Protein targeting to exosomes/microvesicles by plasma membrane anchors. J Biol Chem. 2011;286(16):14383-14395.

173. Klammt C, Schwarz D, Lohr F, Schneider B, Dotsch V, Bernhard F. Cell-free expression as an emerging technique for the large scale production of integral membrane protein. FEBS J. 2006;273(18): 4141-4153.

174. Reckel S, Sobhanifar S, Durst F, et al. Strategies for the cell-free expression of membrane proteins. Methods Mol Biol. 2010;607:187-212.

175. Schwarz D, Dotsch V, Bernhard F. Production of membrane proteins using cell-free expression systems. Proteomics. 2008;8(19): 3933-3946.

176. Hovijitra NT, Wuu JJ, Peaker B, Swartz JR. Cell-free synthesis of functional aquaporin $\mathrm{Z}$ in synthetic liposomes. Biotechnol Bioeng. 2009;104(1):40-49.

177. Kaneda M, Nomura SM, Ichinose S, et al. Direct formation of proteoliposomes by in vitro synthesis and cellular cytosolic delivery with connexin-expressing liposomes. Biomaterials. 2009;30(23-24): 3971-3977.

178. Malam Y, Loizidou M, Seifalian AM. Liposomes and nanoparticles: nanosized vehicles for drug delivery in cancer. Trends Pharmacol Sci. 2009;30(11):592-599.

179. Tarahovsky YS. "Smart" liposomal nanocontainers in biology and medicine. Biochemistry (Mosc). 2010;75(7):811-824.

180. Wang HX, Kolesnikova TV, Denison C, Gygi SP, Hemler ME. The C-terminal tail of tetraspanin protein CD9 contributes to its function and molecular organization. J Cell Sci. 2011;124(Pt 16):2702-2710.

181. Bartels CL, Tsongalis GJ. MicroRNAs: novel biomarkers for human cancer. Clin Chem. 2009;55(4):623-631.

182. Henry JC, Azevedo-Pouly AC, Schmittgen TD. microRNA replacement therapy for cancer. Pharm Res. 2011;28(12):3030-3042.

183. Kota J, Chivukula RR, O’Donnell KA, et al. Therapeutic microRNA delivery suppresses tumorigenesis in a murine liver cancer model. Cell. 2009;137(6):1005-1017.

184. Liu C, Kelnar K, Liu B, et al. The microRNA miR-34a inhibits prostate cancer stem cells and metastasis by directly repressing CD44. Nat Med. 2011;17(2):211-215.

185. Gambari R, Fabbri E, Borgatti M, et al. Targeting microRNAs involved in human diseases: a novel approach for modification of gene expression and drug development. Biochem Pharmacol. 2011;82(10): 1416-1429.

186. Kota SK, Balasubramanian S. Cancer therapy via modulation of micro RNA levels: a promising future. Drug Discov Today. 2010;15(17-18): 733-740.

187. Matsubara H, Takeuchi T, Nishikawa E, et al. Apoptosis induction by antisense oligonucleotides against miR-17-15p and miR-20a in lung cancers overexpressing miR-17-92. Oncogene. 2007;26(41):6099-6105.

188. Segura MF, Hanniford D, Menendez S, et al. Aberrant miR-182 expression promotes melanoma metastasis by repressing FOXO3 and microphthalmia-associated transcription factor. Proc Natl Acad Sci US A. 2009;106(6):1814-1819. 
189. Si ML, Zhu S, Wu H, Lu Z, Wu F, Mo YY. miR-21-mediated tumor growth. Oncogene. 2007;26(19):2799-2803.

190. SylvestreY, De Guire V, Querido E, et al. AnE2F/miR-20a autoregulatory feedback loop. J Biol Chem. 2007;282(4):2135-2143.

191. Lu Y, Roy S, Nuovo G, et al. Anti-microRNA-222 (anti-miR-222) and -181B suppress growth of tamoxifen-resistant xenografts in mouse by targeting TIMP3 protein and modulating mitogenic signal. $J$ Biol Chem. 2011;286(49):42292-42302.

192. Yang YP, Chien Y, Chiou GY, et al. Inhibition of cancer stem cell-like properties and reduced chemoradioresistance of glioblastoma using microRNA145 with cationic polyurethane-short branch PEI. Biomaterials. 2012;33(5):1462-1476.

193. Xu D, Takeshita F, Hino Y, et al. miR-22 represses cancer progression by inducing cellular senescence. J Cell Biol. 2011;193(2):409-424.
194. Kim DH, Rossi JJ. Strategies for silencing human disease using RNA interference. Nat Rev Genet. 2007;8(3):173-184.

195. Guo P, Coban O, Snead NM, et al. Engineering RNA for targeted siRNA delivery and medical application. Adv Drug Deliv Rev. 2010;62(6):650-666.

196. Szoka F. Molecular biology. The art of assembly. Science. 2008; 319(5863):578-579.

197. Lakhal S, Wood MJ. Exosome nanotechnology: an emerging paradigm shift in drug delivery: exploitation of exosome nanovesicles for systemic in vivo delivery of RNAi heralds new horizons for drug delivery across biological barriers. Bioessays. 2011;33(10):737-741.
International Journal of Nanomedicine

\section{Publish your work in this journal}

The International Journal of Nanomedicine is an international, peerreviewed journal focusing on the application of nanotechnology in diagnostics, therapeutics, and drug delivery systems throughout the biomedical field. This journal is indexed on PubMed Central,

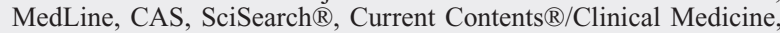

\section{Dovepress}

Journal Citation Reports/Science Edition, EMBase, Scopus and the Elsevier Bibliographic databases. The manuscript management system is completely online and includes a very quick and fair peer-review system, which is all easy to use. Visit http://www.dovepress.com/ testimonials.php to read real quotes from published authors.

Submit your manuscript here: http://www.dovepress.com/international-journal-of-nanomedicine-journal 